\title{
Sistem Keamanan Ruangan Laboratorium Politeknik Sains dan Teknologi Wiratama Maluku Utara Menggunakan Sensor PIR (Passive Infra Red) dengan Metode Pengembangan Prototyping Berbasis Mikrokontroller ATmega328
}

\author{
Basri Albar ${ }^{1}$, Arisandy Ambarita ${ }^{2}$, Adelina Ibrahim ${ }^{3}$ \\ Program Studi Teknik Komputer ${ }^{1}$, Program Studi Manajemen Informatika ${ }^{2}$ \\ Politeknik Sains dan Teknologi Wiratama Maluku Utara \\ Program Studi Teknik Informatika ${ }^{3}$, Universitas Muhammadiyah Maluku Utara \\ hello.basri@gmail.com
}

\begin{abstract}
Abstrak
Penelitian ini bertujuan merancang suatu sistem keamanan tambahan untuk mencegah tindak kejahatan di ruangan laboratorium komputer Politeknik Sains dan Teknologi Wiratama Maluku Utara. Metode pengembangan sistem yang digunakan pada penelitian ini adalah metode prototype. Pembuatan sistem keamanan dengan memanfaatkan mikrokontroler ATmega328 (atau dikenal dengan nama Arduino Uno R3) yang diaplikasikan dengan variasi input berupa sensor PIR dan output-nya berupa buzzer dan lampu LED. Sensor PIR digunakan untuk mendeteksi perubahan suhu akibat adanya pergerakan tubuh manusia. Perubahan nilai suhu yang dideteksi oleh sensor PIR yang berlogika high kemudian diproses oleh Arduino Uno yang akhirnya mengeluarkan sinyal output berupa bunyi alarm pada buzzer dan indikator pada lampu $L E D$. Dengan adanya sistem keamanan ini diharapkan dapat meningkatkan keamanan ruangan dari tindak kejahatan dan mengurangi tindak kriminalitas pada laboratorium Politeknik Sains dan Teknologi Wiratama Maluku Utara

Kata kunci: Sistem Keamanan, Model Prototyping, Sensor PIR, Mikrokontroler ATmega328

Abstract

This study aims to design an additional security system to prevent crime in the computer laboratory room of Politeknik Sains dan Teknologi Wiratama Maluku Utara. The system development method used in this study is the prototype method. Making a security system by utilizing the ATmega328 microcontroller (otherwise known as Arduino Uno R3) is applied with a variety of inputs in the form of a PIR sensor and its output in the form of buzzers and LED lights. PIR sensors are used to detect temperature changes due to the movement of the human body. Changes in temperature values detected by PIR sensors which are high logic are then processed by Arduino Uno which finally outputs an output signal in the form of an alarm on the buzzer and an indicator on the LED light. The existence of this security system is expected to improve the security of the room from crime and reduce criminal acts in the laboratory Politeknik Sains dan Teknologi Wiratama Maluku Utara.
\end{abstract}

Keywords: Security System, Prototyping Model, PIR Sensor, ATmega328 Microcontroller

PENDAHULUAN

Keamanan ruangan merupakan suatu hal yang sangat penting untuk diperhatikan, dan untuk menciptakan keamanan tersebut, banyak hal yang dapat kita lakukan dengan pemanfaatan teknologi saat ini, salah satunya pada ruang laboratorium komputer. Laboratorium komputer yang mempunyai tingkat keamanan yang khusus sangat dibutuhkan oleh perguruan tinggi pada zaman sekarang. Ruang laboratorium komputer di Politeknik Sains dan Teknologi Wiratama Maluku Utara 
merupakan yang saat ini juga membutuhkan sistem keamanan khusus. Karena semakin maraknya tindak kriminal pencurian yang terjadi belakangan ini, maka diperlukan sistem keamanan tersebut.

Dengan memanfaatkan teknologi yang semakin maju saat ini, pembuatan sistem keamanan tambahan pada laboratorium komputer Politeknik Sains dan Teknologi Wiratama dapat dilakukan dengan menggunakan mikrokontroler dan berbagai sensor masukan, salah satunya adalah sensor PIR. Sensor Passive Infra Red (PIR) saat ini sudah banyak digunakan dalam bidang keamanan. Passive Infra Red (PIR) sendiri dalam bidang keamanan digunakan untuk pengindera. Adanya rangsangan yang dihasilkan oleh suatu unsur eksternal pada sebuah sensor menyebabkan rangkaian bekerja secara otomatis sesuai dengan program yang telah dibuat untuk menjalankan suatu perangkat berupa alarm. Dalam pengoperasian rangkaian ini, dibutuhkan sebuah alat pengontrol berupa mikrokontroler Atmega328 (biasa dikenal dengan nama Arduino Uno R3) dalam paket perangkat keras yang telah diprogram dan mengolah data input dari pembacaan sensor bekerja berupa logika 1 atau 0 . Reaksi tersebut akan mengaktifkan beban berupa alarm peringatan. Maka dari itu, peneliti ingin memanfaatkan alat ini dan beserta pendukungnya untuk digunakan sebagai sistem keamanan tambahan di laboratorium Politeknik Sains dan Teknologi Wiratama Maluku Utara

\section{Rumusan Masalah}

Bagaimana merancang sebuah Sistem Keamanan Ruangan Menggunakan Sensor PIR dengan Model Pengembangan Prototyping berbasis Mikrokontroler
ATmega328 dalam meningkatkan Kemanan Ruangan Laboratorium Komputer Politeknik Sains dan Teknologi Wiratama Maluku Utara

\section{Tujuan Penelitian}

1. Merancang Sistem Keamanan Ruangan Laboratorium Politeknik Sains dan Teknologi Wiratama Maluku Utara Menggunakan Sensor PIR (Passive InfraRed) dengan Metode Pengembangan Prototyping Berbasis Mikrokontroller ATmega328.

2. dapat meningkatkan keamanan ruangan dari tindak kejahatan dan mengurangi tindak kriminalitas pada laboratorium Politeknik Sains dan Teknologi Wiratama Maluku Utara

\section{Manfaat Penelitian}

1. Membantu kinerja pihak kampus terutama pada petugas dalam menjaga keamanan laboratorium komputer Politeknik Sains dan Teknologi Wiratama Maluku Utara.

2. Memberikan kemudahan peringatan dini kepada petugas apabila sedang tidak berada di ruangan laboratorium komputer Politeknik Sains dan Teknologi Wiratama Maluku Utara

\section{Tinjauan Pustaka}

Asep Abdul Sofyan, Puput Puspitorini, Dede Baehaki dengan judul Sistem Keamanan Pengendali Pintu Otomatis Berbasis Radio Frequency Identification (RFID) dengan Arduino Uno R3. mengemukakan Dengan kemajuan teknologi tersebut pada era sekarang ini komunikasi bukan hanya digunakan untuk komunikasi antar sesama manusia saja, melainkan antara manusia dengan alat-alat kontrol, seperti sistem pintu otomatis berbasis Radio Frequency Identification 
(RFID) dengan Arduino Uno R3. Banyaknya siswa-siswa yang berkunjung ke ruang kelas lain ketika jam mata pelajaran guru yang kosong. Terjadinya beberapa kali kehilangan peralatan yang ada di ruang kelas atau di ruang labolatorium sehingga keamanannya kurang terjaga dengan baik. Banyak murid yang keluar kelas/bolos sebelum jam mata pelajaran selesai. Untuk itu dibutuhkan sistem pengontrolan pintu secara otomatis sehingga sekolah dapat mengurangi biaya pengeluaran menjadi lebih ringan. Aplikasi ini dibangun dengan menggunakan (RFID) dengan Arduino Uno R3. Tujuan pembuatan aplikasi ini adalah untuk membantu pihak sekolah dalam melakukan pengamanan pintu secara otomatis sehingga dapat membantu sekolah untuk mengurangi pengeluaran biaya keamanan sekolah

Ruri Hartika Zain dengan Judul Penelitian Sistem Keamanan Ruangan Menggunakan Sensor Passive Infra Red (PIR) dilengkapi Kontrol Penerangan Pada Ruangan Berbasis Mikrokontroler ATmega8535 dan Real Time Clock DS1307 mengatakan bahwa Keamanan gedung dan rumah mewah sangat diperlukan untuk mengatasi tindak kejahatan seperti pencurian dan perampokan. Untuk pengamanan gedung dan rumah mewah diperlukan sebuah sistem pengamanan yang dapat diaplikasikan atau digunakan oleh suatu perusahaan. Salah satunya adalah sistem keamanan dengan menggunakan sensor Passive Infra Red (PIR) KC7783R dan mikrokontroler ATmega8535 yang sudah di dukung dengan bahasa pemograman $\mathrm{C}$. Sistem keamanan gedung dan rumah mewah diantaranya menggunakan kamera CCTV yang dipantau oleh operator yang diminta oleh pemilik gedung atau rumah mewah tersebut. Kamera CCTV ada yang menggunakan sensor IR dan ultrasonik, tetapi dalam penggunaannya juga dibutuhkan sumber sensor lain. Contohnya, sensor otomatis yaitu PIR sensor dengan jangkauan yang cukup panjang.

\section{LANDASAN TEORI \\ Pengertian Arduino}

Arduino adalah perangkat keras sekaligus perangkat lunak yang memungkinkan siapa saja melakukan pembangunan prototype suatu rangkaian elektronika yang berbasis mikrokontroler dengan mudah dan cepat. Secara lebih khusus, papan arduino berbasis mikrokontroler yang dikeluarkan oleh perusahaan Atmel, salah satunya adalah Atmega328P (Kadir: 2016).

\section{Software Arduino}

Menurut Sulaiman (2012), arduino diciptakan untuk para pemula bahkan yang tidak memiliki basic bahasa pemrograman sama sekali karena menggunakan bahasa $\mathrm{C}++$ yang telah dipermudah melalui library

\section{Arsitektur Mikrokontroler}

Mikrokontroler adalah sebuah sistem komputer yang seluruh atau sebagian besar elemennya dikemas dalam satu keping IC (Integrated Circuits) sehingga sering disebut mikrokomputer cip tunggal. Lebih lanjut, mikrokontroler merupakan sistem komputer yang mempunyai satu atau beberapa tugas yang sangat spesifik, berbeda dengan Personal Computer (PC) yang memiliki beragam fungsi (Taufiq, 2010).

Sensor Passive Infrared Receiver (PIR) 
PIR (Passive Infrared Receiver) merupakan sebuah sensor berbasiskan infrared. Akan tetapi, tidak seperti sensor infra merah kebanyakan yang terdiri dari IRLED dan fototransistor. PIR tidak memancarkan apapun seperti IRLED. Sesuai dengan namanya 'Passive', sensor ini hanya merespon energi dari pancaran sinar infra merah pasif yang dimiliki oleh setiap benda yang terdeteksi olehnya. Benda yang bisa dideteksi oleh sensor ini biasanya adalah tubuh manusia (learn.adafruit.com. 2014). yang mempunyai perannya di antaranya Fresnel lens, IR filter, pyroelectric sensor, amplifier, dan comparator. Berikut gambar bagian-bagian dari sensor PIR:

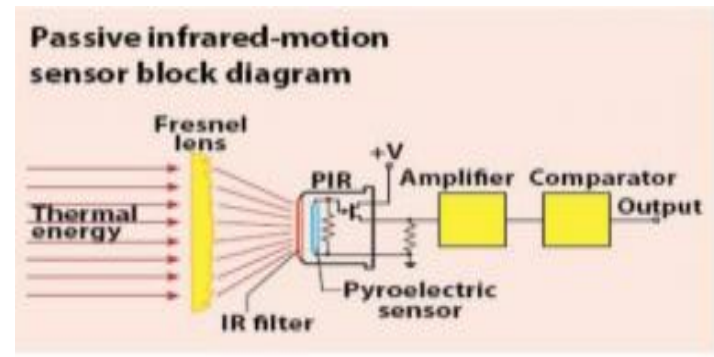

Gambar 1. Bagian utama dari sensor PIR (Sumber: P Sihombing, dkk, 2018)

Sensor PIR itu sendiri memiliki dua slot di dalamnya, masing-masing slot terbuat dari bahan khusus yang sensitif terhadap IR. Lensa yang digunakan di sini tidak benar-benar melakukan banyak hal dan kami melihat bahwa kedua slot dapat 'melihat' melewati jarak tertentu (pada dasarnya sensitivitas sensor). Ketika sensor dalam keadaan idle, kedua slot mendeteksi jumlah IR yang sama, jumlah sekitar terpancar dari ruangan atau dinding atau di luar ruangan. Ketika tubuh hangat seperti manusia atau hewan lewat, ia pertama-tama memotong setengah dari sensor PIR, yang menyebabkan perubahan diferensial positif antara kedua bagian. Ketika tubuh hangat meninggalkan area penginderaan, kebalikannya terjadi, di mana sensor menghasilkan perubahan diferensial negatif. Pulsa perubahan inilah yang terdeteksi.

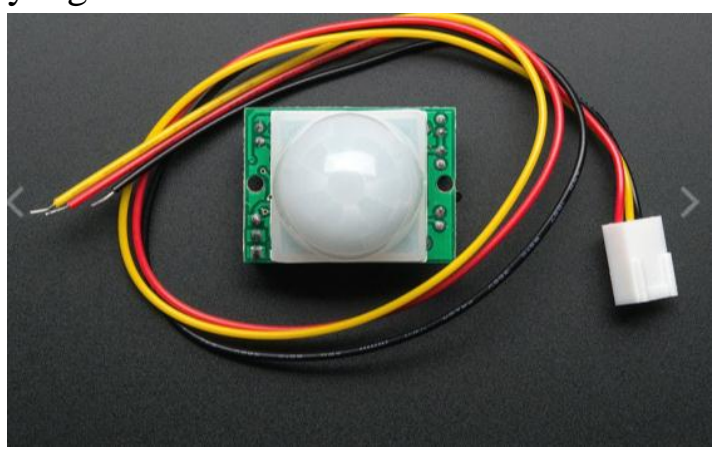

Gambar 2. sensor PIR

(Sumber: learn.adafruit.com, 2014)

\section{Model Pengembangan Prototyping}

Ogedebe, dkk (2012) Prototyping merupakan metode pengembangan perangat lunak, yang berupa model fisik kerja sistem dan berfungsi sebagai versi awal dari sistem. Dengan metode prototyping ini akan dihasilkan prototype sistem sebagai perantara pengembang dan pengguna agar dapat berinteraksi dalam proses kegiatan pengembangan sistem informasi.

Prototyping dimulai dengan pengumpulan kebutuhan, melibatkan pengembang dan pengguna sistem untuk menentukan tujuan, fungsi dan kebutuhan operasional sistem. Langkah-langkah dalam prototyping adalah sebagai berikut :

1. Pengumpulan Kebutuhan.

2. Proses desain yang cepat.

3. Membangun prototipe.

4. Evaluasi dan perbaikan.

\section{METODE PENELITIAN}

\section{Metode Pengembangan Sistem}

Metode pengembangan model prototype terdiri dari beberapa mekanisme, di antaranya:

1. Identifikasi Kebutuhan 
Untuk membangun sistem keamanan ruangan laboratorium komputer, maka dalam penelitian ini yang dibutuhkan adalah spesifikasi ruangan laboratorium yang didapat dari hasil studi literatur pustaka, observasi langsung di ruangan laboratorium dan wawancara kepada petugas. Untuk listing source code program alat yang digunakan adalah Arduino IDE serta hardware yang dibutuhkan untuk membangun sistem berupa mikrokontroler ATmega328, sensor PIR, buzzer alarm, breadboard, serta kabel jumper.

2. Membangun Prototype

Membangun prototyping dengan membuat sebuah perancangan sementara. Pada penelitian ini, dimulai dari pembuatan skematik sistem menggunakan software Fritzing dan untuk membuat alur kerja rangkaian sistem dibantu oleh Microsoft Visio 2007 serta pemasangan hardware sistem keamanan dan alat yang telah dirangkai akan dipasangkan pada sebuah maket ruangan sebagai simulasi dari rangkaian yang dibuat.

3. Menguji Prototype

Untuk pengujian prototype pada ruangan dengan jarak uji coba mulai dari $10 \mathrm{~cm}$ sampai dengan $60 \mathrm{~cm}$ dengan delay time yang akan diuji mulai dari 0,3 sekon sampai dengan 5 menit.

4. Memperbaiki Prototype (Evaluasi Sistem)

Tahapan memperbaiki prototype sistem yaitu meliputi perbaikan source code program Arduino IDE yang mengalami error dan kesalahan dari perangkaian alat yang dirancang.

5. Mengembangkan Versi Produksi (Penerapan Sistem)
Rangkaian sistem keamanan yang telah diuji coba dan telah dilakukan perbaikan akan diletakkan pada pintu ruangan laboratorium komputer.

\section{Alur Penelitian}

Alur penelitian merupakan urutan penelitian yang akan dikerjakan dalam pengembangan sistem

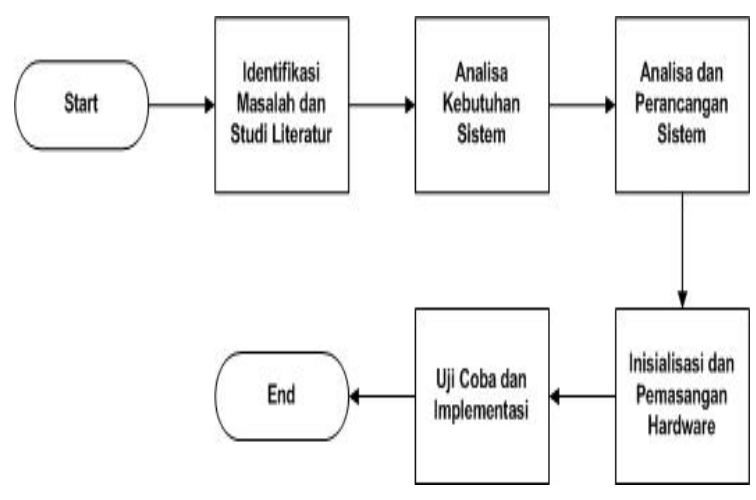

Gambar 2. Alur Penilitian

\section{ANALISIS DAN PERANCANGAN \\ Analisis Kebutuhan Sistem \\ Spesifikasi Perangkat Keras (hardware).}

Perangkat keras yang digunakan pada penelitian ini adalah:

1. Laptop merk ACER.

2. Processor Intel $(R)$ Celeron $(R) C P U$ N2840@2.16GHz2.16 GHz.

3. RAM 2,00 GB.

4. Harddisk $500 \mathrm{~GB}$.

5. Mikrokontroler ATmega328 (Arduino Uno R3).

6. Breadboard.

7. Kabel Jumper.

8. Sensor PIR HC-SR501

9. Buzzer.

10. Kabel USB.

11. Lampu LED.

\section{Spesifikasi Perangkat Lunak (Software)}

Perangkat lunak yang digunakan peneliti di antaranya: 
1. Windows 10 Pro 64-bit Operation System

2. Arduino IDE 1.8.5.

3. Microsoft Visio 2007

4. Fritzing 0.8.7.

\section{Rancangan Usulan Sistem}

Rancangan usulan sistem merupakan alur rancangan cara kerja sistem yang akan dibangun

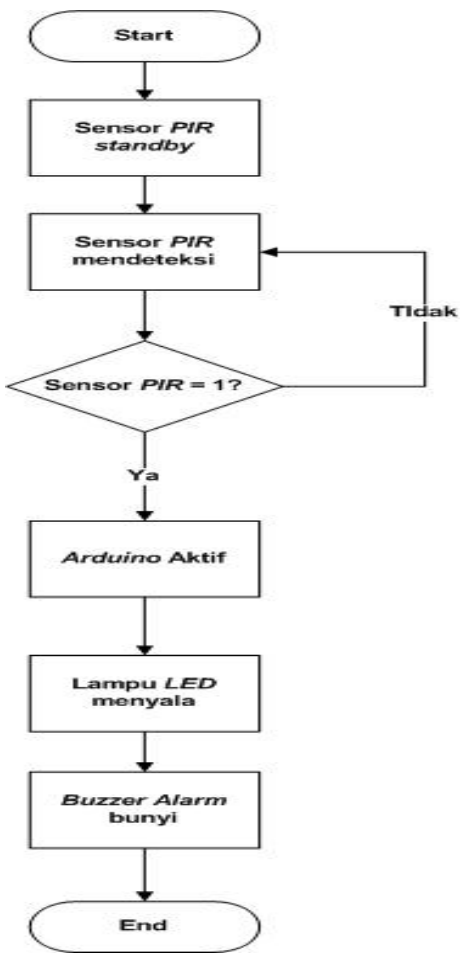

Gambar 3. Rancangan usulan sistem

\section{Perancangan Diagram Blok Sistem}

Rancangan sistem yang akan dibangun terdiri atas tiga bagian yaitu piranti masukan, mikrokontroler, dan piranti keluaran. Pada piranti masukan terdapat sensor yang merupakan sumber perintah bagi mikrokontroler Arduino Uno R3. Adapun piranti masukan berupa jenis sensor Passive Infra Red (PIR). Sedangkan pada piranti keluaran yaitu terdapat lampu LED dan Buzzer Alarm yang digunakan sebagai indikator.

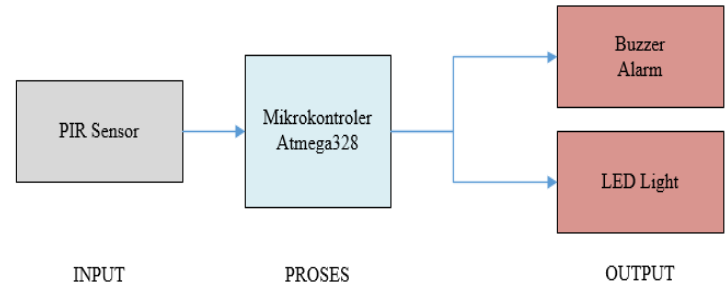

Gambar 4. Rancangan Diagram Blok

\section{Rancangan Skema}

Perancangan keseluruhan sistem perangkat keras (hardware) meliputi perancangan dari bagian pengiriman data sensor pada mikrokontroler dengan menggunakan Sensor PIR sampai pada bagian buzzer sebagai alarm

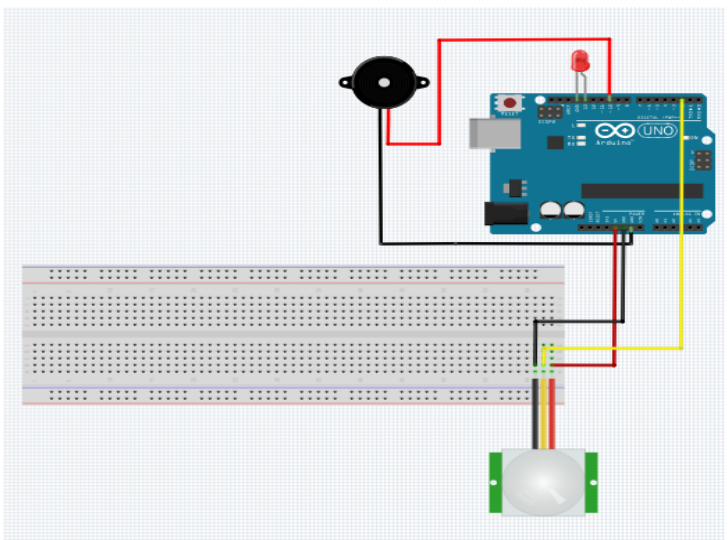

Gambar 5. Rangkaian Skema

\section{Rancangan Ruangan Laboratorium}

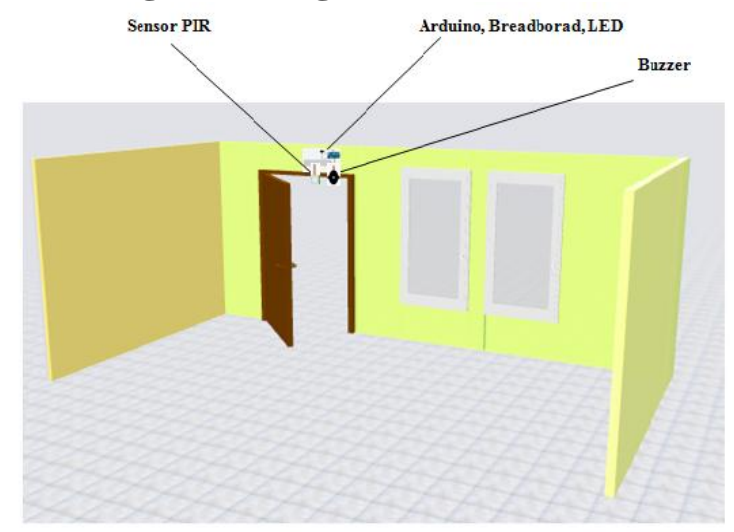

Gambar 6. Rangkaian Skema

Output pada rangkaian berupa buzzer sebagai alarm akan diuji hasilnya dengan menentukan tepat atau tidaknya kondisi dengan perancangan software. Kondisi di 
mana sensor PIR harus bernilai high agar dapat diproses oleh mikrokontroler. Sensor PIR akan diletakkan di atas pintu menghadap ke bawah untuk melakukan pendeteksian ada atau tidaknya gerakan yang melewati pintu. Sedangkan buzzer akan diletakkan di posisi yang tepat agar bunyi yang dihasilkan terdengar jelas

\section{IMPLEMENTASI DAN PEMBAHASAN} Pengujian Hasil Board Arduino Uno

Untuk mengetahui apakah board Arduino yang dipakai bekerja dengan baik atau tidak. Alat tambahan yang digunakan untuk mengetahui kinerja board Arduino Uno adalah lampu $L E D$

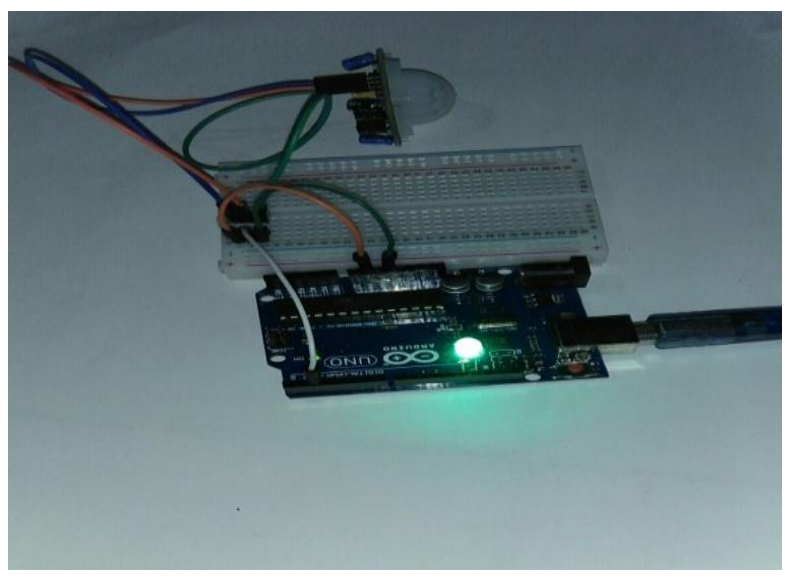

Gambar 7. Rangkaian board Sensor PIR

\section{Pengujian source code pada board arduino}

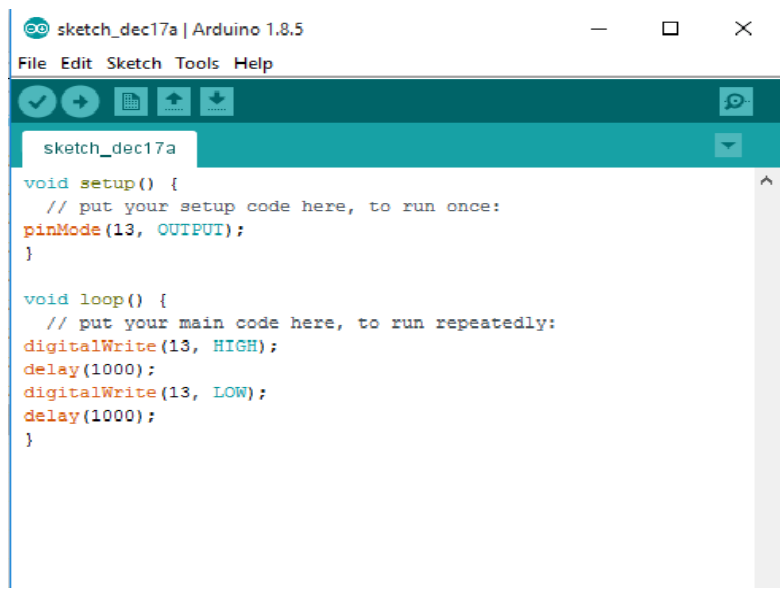

Gambar 8. Rangkaian board Sensor PIR
Dengan meng-upload source code program di atas, maka analisis hasil yang didapat bahwa lampu $L E D$ akan menyala selama 1 detik dan kemudian padam selama 1 detik, demikian seterusnya. maka rangkaian board arduino dalam keadaan baik

Tabel 1. Hasil Pengujian Alat Pada Ruangan ketika ada gerakan

\begin{tabular}{|c|c|c|c|c|c|c|}
\hline $\begin{array}{l}\text { Jara } \\
\mathrm{k} \\
\text { Sen } \\
\text { sor } \\
\text { PIR } \\
\text { (me } \\
\text { ter) }\end{array}$ & $\begin{array}{l}\text { Del } \\
\text { ay } \\
\text { Tim } \\
e \\
\text { (Wa } \\
\text { ktu } \\
\text { Tun } \\
\text { da } \\
\text { Pad } \\
\text { am) }\end{array}$ & $\begin{array}{l}\text { Kon } \\
\text { disi } \\
\text { Ada } \\
\text { Gera } \\
\text { kan } \\
\text { (Wa } \\
\text { ktu } \\
\text { Tun } \\
\text { da } \\
\text { Nyal } \\
\text { a) }\end{array}$ & $\begin{array}{l}\text { Tega } \\
\text { ngan } \\
\text { Outp } \\
\text { ut } \\
\text { VDC }\end{array}$ & $\begin{array}{l}\text { Lam } \\
\mathrm{pu} \\
\text { LED }\end{array}$ & $\begin{array}{l}\text { Buz } \\
\text { zer }\end{array}$ & $\begin{array}{l}\text { Ketera } \\
\text { ngan }\end{array}$ \\
\hline $1 \mathrm{~m}$ & $\begin{array}{l}1 \\
\text { men } \\
\text { it }\end{array}$ & $\begin{array}{l}5 \\
\text { deti } \\
k\end{array}$ & 5 volt & $\begin{array}{l}\text { Men } \\
\text { yala }\end{array}$ & $\begin{array}{l}\mathrm{Bu} \\
\text { nyi }\end{array}$ & $\begin{array}{l}\text { Terdet } \\
\text { eksi }\end{array}$ \\
\hline $2 \mathrm{~m}$ & $\begin{array}{l}5 \\
\text { deti } \\
\mathrm{k}\end{array}$ & $\begin{array}{l}3 \\
\text { deti } \\
\mathrm{k}\end{array}$ & 5 volt & $\begin{array}{l}\text { Men } \\
\text { yala }\end{array}$ & $\begin{array}{l}\mathrm{Bu} \\
\text { nyi }\end{array}$ & $\begin{array}{l}\text { Terdet } \\
\text { eksi }\end{array}$ \\
\hline $3 \mathrm{~m}$ & $\begin{array}{l}1 \\
\text { men } \\
\text { it }\end{array}$ & $\begin{array}{l}5 \\
\text { deti } \\
k\end{array}$ & 5 volt & $\begin{array}{l}\text { Men } \\
\text { yala }\end{array}$ & $\begin{array}{l}\mathrm{Bu} \\
\text { nyi }\end{array}$ & $\begin{array}{l}\text { Terdet } \\
\text { eksi }\end{array}$ \\
\hline $4 \mathrm{~m}$ & $\begin{array}{l}1 \\
\text { men } \\
\text { it }\end{array}$ & $\begin{array}{l}9 \\
\text { deti } \\
k\end{array}$ & 5 volt & $\begin{array}{l}\text { Men } \\
\text { yala }\end{array}$ & $\begin{array}{l}\mathrm{Bu} \\
\text { nyi }\end{array}$ & $\begin{array}{l}\text { Terdet } \\
\text { eksi }\end{array}$ \\
\hline $5 \mathrm{~m}$ & $\begin{array}{l}5 \\
\text { men } \\
\text { it }\end{array}$ & $\begin{array}{l}13 \\
\text { deti } \\
k\end{array}$ & 5 volt & $\begin{array}{l}\text { Men } \\
\text { yala }\end{array}$ & $\begin{array}{l}\mathrm{Bu} \\
\text { nyi }\end{array}$ & $\begin{array}{l}\text { Terdet } \\
\text { eksi }\end{array}$ \\
\hline
\end{tabular}

Pada tabel di atas, analisis hasil yang didapat bahwa ketika sensor PIR mendeteksi adanya gerakan atau dalam keadaan $H I G H$, ditandai dengan bunyi dari buzzer dan lampu LED dalam keadaan menyala. Uji coba dilakukan dengan mengatur waktu tunda padam diatur mulai dari 5 detik sampai dengan 5 menit pada sensor PIR dan waktu tunda menyala yang didapat mulai dari 3 detik sampai dengan 13 detik dengan jarak sensor uji coba mulai dari 1 meter sampai dengan 5 meter, maka uji coba berhasil 


\section{KESIMPULAN}

1. Sistem Keamanan Ruangan Laboratorium Politeknik Sains dan Teknologi Wiratama Maluku Utara Menggunakan Sensor PIR (Passive Infra Red) dengan Metode Pengembangan Prototyping Berbasis Mikrokontroller ATmega328 (Arduino Uno R3) yang terintegrasi dengan sensor PIR serta buzzer sangat bermanfaat karena dapat membantu dalam meningkatkan keamanan ruangan dari tindak kejahatan dibanding menggunakan kunci konvesional saja.

2. Sensor PIR aktif apabila adanya perubahan sinyal infrared yang diterima oleh sensor akibat gerakan manusia. Ketika aktif, sensor memberikan logika HIGH pada Arduino Uno dengan tegangan yang diberikan 5V DC dengan jarak jangkauan maksimal sensor PIR yang diuji coba maksimal 5 meter.

\section{Saran}

1. Output pada rangkaian sistem keamanan pada penelitian ini hanya berupa buzzer alarm yang hanya bisa memberikan peringatan apabila petugas masih berada di lokasi. Maka dari itu, bagi pengembang agar bisa menambahkan peringatan dini kepada petugas berupa notifikasi SMS yang terintegrasi langsung dengan alarm ketika petugas tidak berada di lokasi.

2. Untuk penelitian selanjutnya disarankan agar sebaiknya media output-nya dapat dikembangkan dan dikontrol oleh perangkat tambahan seperti operasi sistem Android, CCTV, QR Code, atau Radio Frequency Identification (RFID).

\section{DAFTAR PUSTAKA}

Asep Abdul Sofyan, Puput Puspitorini, Dede Baehaki, Sistem Keamanan Pengendali Pintu Otomatis Berbasis Radio Frequency Identification (RFID) Dengan Arduino Uno R3, JURNAL SISFOTEK GLOBAL, Vol. 7 No. 1 Maret 2017, ISSN : $2088-1762$

Ruri Hartika Zain, Sistem Keamanan Ruangan Menggunakan Sensor Passive Infra Red (PIR) dilengkapi Kontrol Penerangan Pada Ruangan Berbasis Mikrokontroler ATmega 8535 dan Real Time Clock DS1307, Jurnal Teknologi Informasi \& Pendidikan, Vol 6 No 1 Maret 2013, ISSN : $2086-4981$

Ogedebe, P. M. \& Jacob, B. P., 2012. Software Prototyping: A Strategy to Use When User Lacks Data Processing Experience. ARPN Journal of Systems and Software, II(6).

Kadir, Abdul (2016). Simulasi Arduino. Jakarta: Elex Media Komputindo.

Sulaiman, Arif (2012). Arduino: Mikrokontroler Bagi Pemula hingga Mahir. Bulletin Balai Elektronika

Taufiq, Dwi Septian Suyadhi (2010). Buku Pintar Robotika. Yogyakarta: ANDI

P Sihombing, Y M Siregar, J T Tarigan, I Jaya and A Turnip, Development of building security integration system using sensors, microcontroller and GPS (Global Positioning System) based android smartphone, Journal of Physics: Conference Series, 2nd International Conference on Computing and Applied Informatics 2017, DOI: $10.1088 / 1742-$ 6596/978/1/012105

adafruit. (2014, January 28). Retrieved January 28, 2019, from learn.adafruit.com: https://learn.adafruit.com/pirpassive-infrared-proximity-motionsensor/how-pirswork. 